\title{
Deformation Monitoring of a Simply Supported Railway Bridge under Varying Dynamic Loads
}

\author{
K. Faulkner, F. Huseynov, J. Brownjohn \& Y. Xu \\ Vibration Engineering Section \\ University of Exeter, Exeter, UK
}

\begin{abstract}
Structural health monitoring is a useful tool for evaluating the condition of bridges, with permanent systems installed on bridges which form vital links on the major transport network. The economic cost of the monitoring systems limits their installation on smaller bridges which make up the wider transport network. A short-term monitoring system can be quickly installed and adjusted to suit the requirements of individual bridges. These systems are ideal for rural regions with a high number of single span bridges on isolated road and rail networks. This report will review a single span bridge on a private heritage railway under loading from passing steam engines, including the Flying Scotsman. Acceleration data are used to determine the rotations and deflections of the bridge deck. To verify the data, deflection measurements at mid-span were recorded using a video-based measurement system. The deflection measurements from the accelerometers correlate with the video imagery measurements.
\end{abstract}

\section{INTRODUCTION}

\subsection{Bridge Failures}

Bridge failures pose a significant risk to human life but can also have a major economic impact on the affected regions. The collapse of the I-35 W bridge in Minnesota, US in 2007 killed 13 people and led to a loss of US\$17 million in 2007 and US\$43 million in 2008, excluding any of the indirect costs (Deng et al. 2015). Across Europe the infrastructure is ageing, with an estimate of $30 \%$ of bridges exceeding 100 years of age (Connolly et al. 2016). In the UK, a review of the railway infrastructure during the period of 1846 to 2013 by van Leeuwen \& Lamb (2014) attributed 138 bridge and culvert failures to flooding alone. A more recent report identified that $25 \%$ of the 603,168 bridges in the United States are rated as deficient by the Federal Highways Agency (FHWA) (Elsaid \& Seracino 2012). Elsaid \& Seracino (2012) further reported that the American Association of State Highway and Transport Officials (AASHTO) identified in 2009 that 50\% of the bridges in the US are over 40 years and without sufficient knowledge of their current condition. A detailed review of the causes and mechanisms of bridge failure was performed by Deng et al. (2015).

Structural health monitoring (SHM) of large multispan bridges is becoming increasingly commonplace, with systems been retrofitted to older bridges and with complex data acquisition systems installed on new builds. A review of SHM techniques was carried out by Webb et al. (2014) who categorised SHM into five categories; (1) anomaly detection, (2) sensor deployment studies, (3) model validation, (4) threshold check and (5) damage detection. Sohn and Farrar (2001) further categorised damage detection into five categories, building on previous work performed by Rytter (1993): (1) identification of the presence of damage in a structure, (2) localisation of the damage, (3) identification of the type of damage, (4) quantification of the severity of the damage and (5) prediction of the remaining service life of the structure.

There is a recent trend towards damage detection, particularly towards identifying damage through a decrease in the natural stiffness of a structure. Brownjohn et al. (2011) reviewed vibration-based damage detection techniques, but determined that for damage detection, vibration-based methods are not suitable for all but the most severe cases of damage. This study will instead follow the form of a sensor deployment study, with the intention to measure a series of parameters to determine the performance of the bridge under varying loading conditions.

Predominantly SHM systems are installed on long span bridges, which are vital links on major 
transport routes, due to the cost of both installing the instrumentation and also the processing cost required to correctly interpret the data. This study will focus on a short span bridge on a heritage railway, as the bridge is representative of a large number of the smaller bridges which make up the wider transport network across the country, particularly in rural areas. The aim is to eventually develop a system that can be easily transported between a number of bridges and can be quickly adapted to fit the testing requirements of each bridge.

\section{WEST SOMERSET RAILWAY}

The West Somerset Railway (WSR) is the longest heritage railway in England, with almost 23 miles of track servicing 10 stations. The railway, located in South West England, was opened in 1862 and was originally servicing villages between Taunton and Watchet. The service was further expanded in 1874 as far as Minehead.

The route was closed by National Rail in 1971 but re-opened in 1976 to service local routes with predominantly diesel locomotives. By 1986, the railway was operating as a heritage railway using mainly steam-powered locomotives, travelling between Bishops Lydeard and Minehead. The railway predominantly operates through the Spring to Autumn months, with additional special services in place throughout the year.

\subsection{Mineral Line Bridge}

The Mineral Line Bridge, located to the west of Watchet station, was originally designed to carry the route over the West Somerset Mineral Railway, which now operates as a bridleway open to the public. The bridge is a $14.8 \mathrm{~m}$ steel girder single span bridge, with two masonry abutments and with a single track running on it. The abutments are orientated with a skew angle of $60^{\circ}$ to the main beams of the bridge.

The bridge was originally constructed in the $1870 \mathrm{~s}$ of wrought iron plate girders, carrying a timber deck supporting the ballasted track bed. The abutments were constructed from stone. A comprehensive maintenance and repair programme to the bridge was carried out in 2011.

\subsection{Locomotives}

The service is predominantly serviced by steampowered locomotives, but a small number of diesel continue to operate on the route. The largest and most powerful locomotive owned by the WSR is the Raveningham Hall, weighing 76.4 tonnes with a
Table 1: Steam locomotive details

\begin{tabular}{llll} 
Locomotive & Year Built & $\begin{array}{l}\text { Length } \\
{[\mathrm{m}]}\end{array}$ & $\begin{array}{l}\text { Gross Weight } \\
\text { [tonnes] }\end{array}$ \\
\hline Flying Scotsman & 1923 & 21.3 & 97.8 \\
Raveningham Hall & 1944 & 19.2 & 76.4 \\
7F Class 2-8-0 53808 & 1925 & 17.9 & 65.8 \\
\hline
\end{tabular}

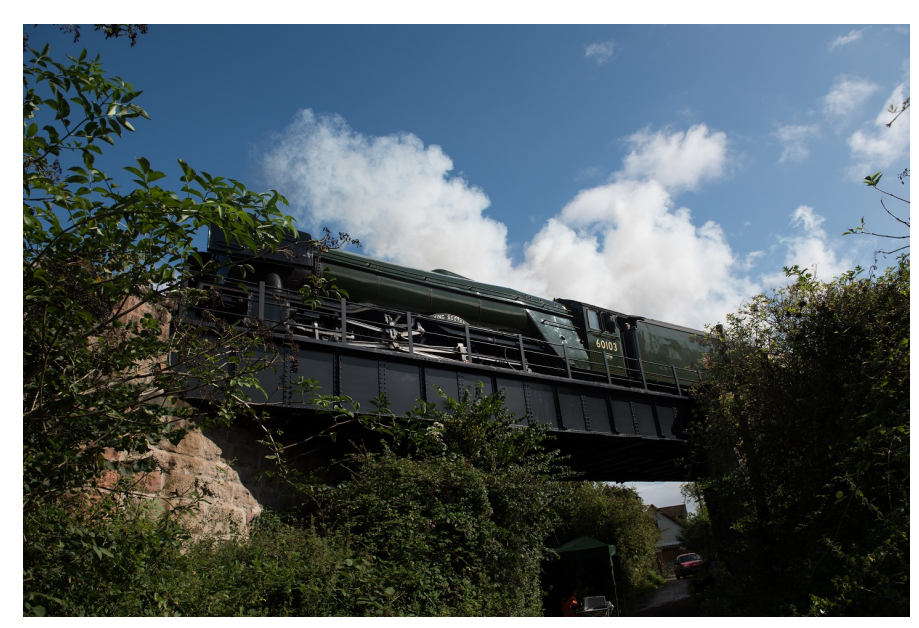

Figure 1: Flying Scotsman locomotive passing over the Mineral Line bridge

single axle load of 17 tonnes.

Every year the National Railway Museum loans the Flying Scotsman locomotive for special tours across the country and in September 2017 the locomotive came to the WSR. The Flying Scotsman has a gross weight of 97.8 tonnes and a varying axle load of 4 to 11 tonnes. Table 1 presents an overview of all the steam locomotives used during the experiment. The weight indicated in Table 1 is the gross weight of the engine when full, but does not include the tender behind. The Flying Scotsman and Ravenington Hall are depicted in Figure 1 and 2, respectively.

The direction of travel for the train determined the position of the locomotive and the tender. In the Watchet to Minehead direction, the engine preceded the tender and on the return route the tender was at the front of the train. The orientation of the engine and the tender is summarised in Table 2. The times for the train are adjusted to the nearest 5 minute mark.

\section{METHODOLOGY}

There were two aims for this study:

1. to determine the rotation of the bridge deck under varied loading conditions;

2. to determine deflection at mid-span under the loading conditions.

\subsection{Rotation}

Inclinometers are the most common method used to measure the angle of rotation of an object, but can only be used to measure the rotation with respect to 
Table 2: Locomotives passing on track

\begin{tabular}{ccllcc} 
Train & Time & Locomotive & Direction & Locomotive Configuration & Number of Carriages \\
\hline 1 & $11: 15$ & Raveningham Hall & BL - MN & Engine & 8 \\
2 & $12: 00$ & Diesel & MN - BL & - & Tender \\
3 & $12: 50$ & Flying Scotsman & MN - BL & Tender & 8 \\
4 & $13: 40$ & Raveningham Hall & MN - BL & Engine & 8 \\
5 & $14: 50$ & Flying Scotsman & BL - MN & Engine & 7 \\
6 & $15: 30$ & 7F Class 2-8-0 53808 & MN - BL & Engine & 8 \\
7 & $16: 10$ & Raveningham Hall & BL - MN & Tender & 8 \\
8 & $17: 30$ & Flying Scotsman & MN - BL & & \\
\hline
\end{tabular}

Notes:

BL : Bishops Lydeard

MN : Minehead

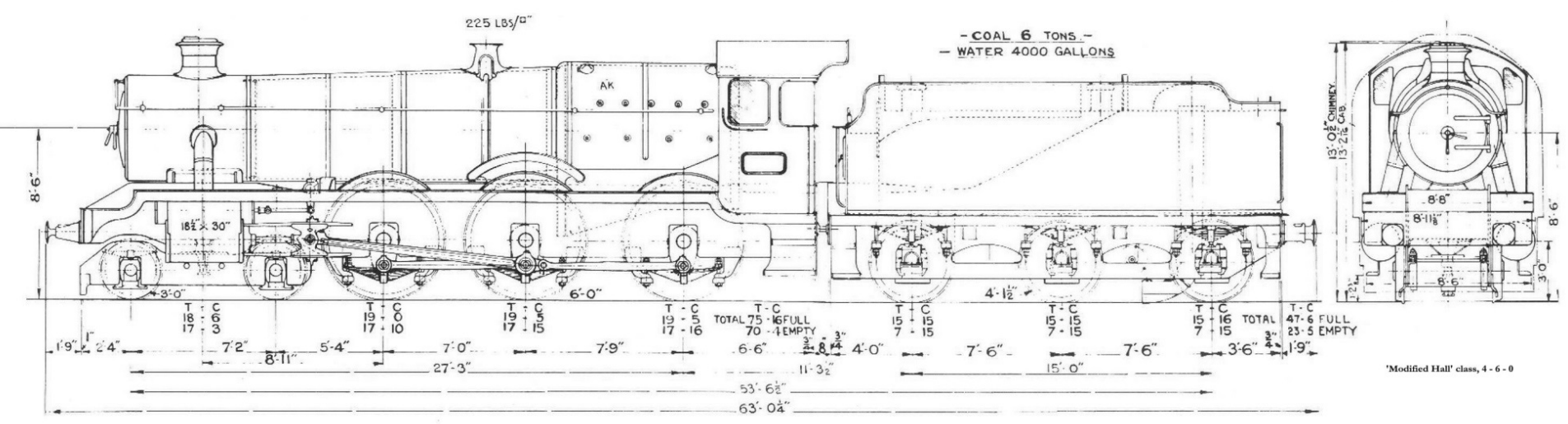

Figure 2: Schematics of the Raveningham Hall locomotive

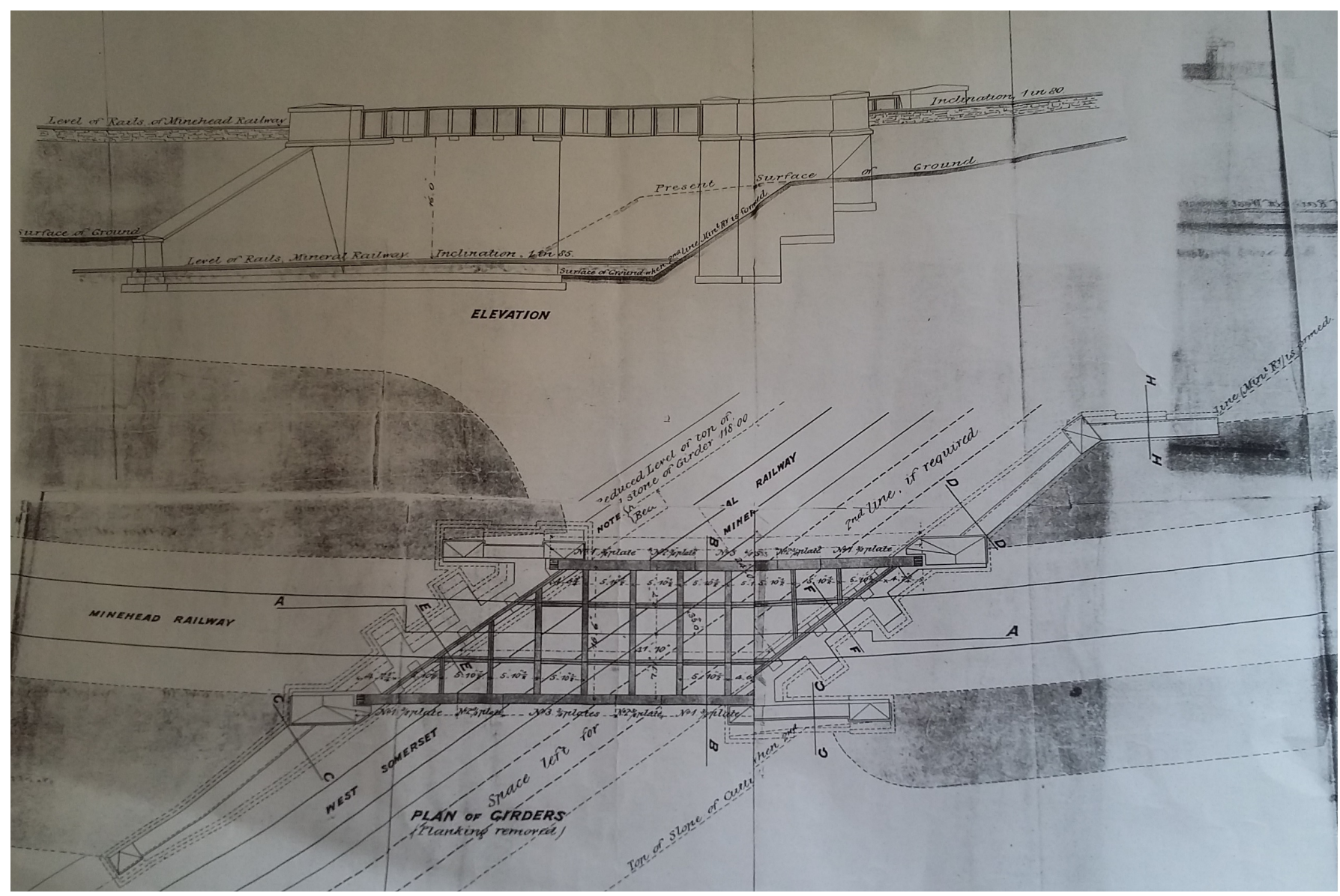

Figure 3: Plan and elevation of the Mineral Line bridge 
gravity. Gyroscopes are frequently used in aerospace and navigational industries but have limited use in structural health monitoring to date. Sung et al. (2013) recommend gyroscopes as a method of refining damage detection techniques at hinged supports of bridges using the measured angular velocity.

For this study, accelerometers were used to define the angles of rotation in place of inclinometers. For this study, a single axis of acceleration was used to determine the angle of rotation. The rotation is determined by projecting the gravity vector on the axes of acceleration.

\subsection{Deflection}

The deflection of the bridge was determined using the accelerometers positioned in Figure 4 and confirmed against the deflections measured using Imetrum cameras. The following procedure for calculating deflection is derived from the method presented by Helmi et al. (2015).

Helmi et al. (2015) proposed a method of deflection calculation using accelerometer and strain gauges. The method can be used without strain gauges if a sufficient number of inclination sensors are installed on the bridge. With 5 test measurement points along the length of the $14.8 \mathrm{~m}$ bridge span, accelerometer data is sufficient to calculate the deflection for this testing scenario. Their method is reproduced in the following paragraphs.

The rotation along the beam is a measurable parameter and can be explained as a $n^{\text {th }}$ order polynomial, expressed as

$$
\begin{array}{r}
\varphi=a_{1} x^{n}+a_{2} x^{n-1}+\cdots+a_{i} x^{n-i+1}+\cdots \\
+a_{n} x \\
+a_{n+1}
\end{array}
$$

where $\varphi$ is the angle of rotation, $x$ is the distance along the bridge and $a_{i}$ is the polynomial coefficient.

Deflection, $\delta$, at any point along the bridge can be determined from the following relationship:

$\delta=\int \varphi d x$

Therefore deflection can be calculated by integrating Equation 1:

$$
\begin{aligned}
\delta=\frac{a_{1}}{(n+1)} x^{n+1}+ & \frac{a_{2}}{n} x^{n}+\cdots+\frac{a_{i}}{n+2-i} x^{n+2-i} \\
& +\cdots+\frac{a_{n}}{2} x^{2}+a_{n+1} x+a_{n+2}
\end{aligned}
$$

If we consider one of the abutments as a reference point, with $x=0$ and $\delta=0$, then $a_{n+2}=0$. Using this, we can simplify Equation 3 to

$$
\begin{aligned}
\delta=\frac{a_{1}}{(n+1)} x^{n+1}+\frac{a_{2}}{n} x^{n} & +\cdots+\frac{a_{i}}{n+2-i} x^{n+2-i} \\
& +\cdots+\frac{a_{n}}{2} x^{2}+a_{n+1} x
\end{aligned}
$$

Using Equation 4, deflection at any point along the bridge can be determined if the polynomial coefficients are known, which is the main advantage of this method. The polynomial coefficients are determined from the following matrices, provided that rotation and deflections are known at $n+1$ or more points:

$$
\left[\begin{array}{ccccc}
x_{\varphi 1}^{n} & x_{\phi 1}^{n-1} & \cdots & x_{\varphi 1} & 1 \\
\vdots & \vdots & \ddots & \vdots & \vdots \\
x_{\varphi i}^{n} & x_{\varphi i}^{n-1} & \cdots & x_{\varphi i} & 1 \\
\frac{x_{\delta 1}^{n+1}}{n+1} & \frac{x_{\delta 1}^{n}}{n} & \ldots & \frac{x_{\delta 1}^{2}}{2} & x_{\delta 1} \\
\vdots & \vdots & \ddots & \vdots & \vdots \\
\frac{x_{\delta k}^{n+1}}{n+1} & \frac{x_{\delta k}^{n}}{n} & \cdots & \frac{x_{\delta k}^{2}}{2} & x_{\delta k}
\end{array}\right]\left[\begin{array}{c}
a_{1} \\
a_{2} \\
\vdots \\
a_{n} \\
a_{n+1}
\end{array}\right]=\left[\begin{array}{c}
\varphi_{1} \\
\vdots \\
\varphi_{i} \\
\delta_{1} \\
\vdots \\
\delta_{k}
\end{array}\right]
$$

\section{TEST SET UP}

In this section we summarise the equipment used during the testing and the sampling programme. Testing was performed on the 5th September 2017; the first day of the Flying Scotsman special tour on the WSR. The locomotive previously travelled the length of the track on the 29 August at reduced speed to confirm the clearances of the platforms and the bridges was sufficient for the locomotive but the passing of the Flying Scotsman on the 5th September was the first time the locomotive passed at full speed agreed for travel along the route.

The purpose of the study was to examine the Mineral Line Bridge under loading from a number of different locomotives, including the Raveningham Hall and the Flying Scotsman. Whilst all bridges and track along the WSR were analysed prior to the arrival of the Flying Scotsman locomotive, to ensure the WSR met the required capacity, this study measured the performance of the structure to confirm the review.

\subsection{Accelerometers}

A total of 11 single axis Honeywell QA750 inertial grade sensors accelerometers were installed on the bridge deck, with three accelerometers installed at quarter-span, mid-span and three quarter-span to measure the $x, y$ and $z$ channels. A single accelerometer was installed in the longitudinal (x) direction at 


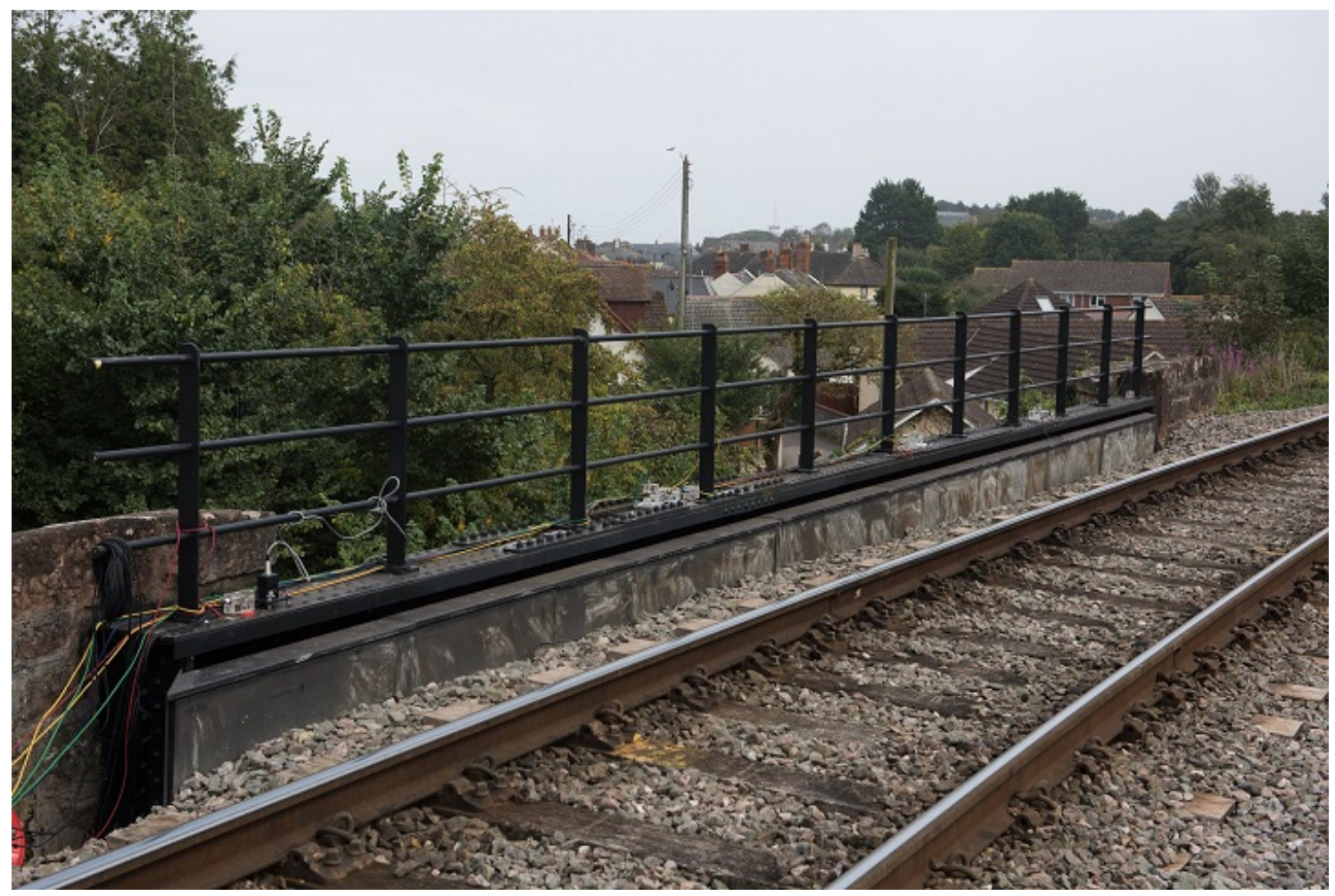

Figure 4: Layout of the accelerometers on the deck

each of the supports.

The accelerometers were positioned on the northern side of the bridge deck, with Test Point 1 located on the eastern abutment, increasing to Test Point 5 on the western abutment. The test layout is presented in Figure 4.

\subsection{Measurements with Video Imagery}

The Imetrum measuring system was developed by the University of Bristol to use image processing to accurately determine deflection and strain measurements in structures. The cameras are particularly useful for outdoor environments where it can be difficult to install measuring devices on large structures.

A total of three cameras were installed at site, with one camera positioned to measure deflection at midspan on the bridge and two cameras positioned to measure deflections on the abutment. The measurements on the abutments are not considered as part of this study. The Imetrum camera layout is presented in Figure 5.

\subsection{Processing}

The data was analysed in MATLAB using the procedures outlined in Section 3. A low pass filter was applied to isolate the accelerations caused by the movement of the train. The data was further smoothed by applying a moving average filter.

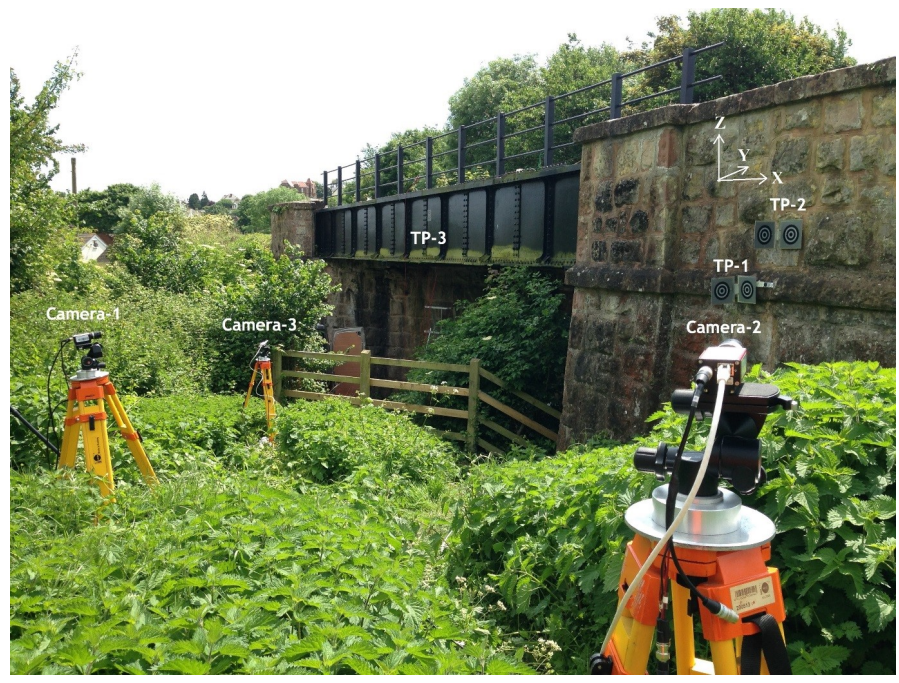

Figure 5: Layout of the Imetrum cameras

\subsection{Test Procedure}

Rotation data was calculated from the accelerometers positioned in the horizontal axes. The deflection at mid-span was later determined using the rotation data obtained from the accelerometers and confirmed against the results of the Imetrum camera.

Data collection commenced before the train was due, to allow sufficient time to analyse the bridge under ambient loading before each test. As the exact arrival time at the bridge was not available, the data collection time before the train approached the bridge varied for each train. The running order of the trains and the direction of travel is recorded in Table 2. 
Table 3: Measured Rotations

\begin{tabular}{clc} 
Train & Locomotive & $\begin{array}{c}\text { Rotation } \\
\text { [deg] }\end{array}$ \\
\hline 1 & Raveningham Hall & 0.093 \\
2 & Diesel & 0.044 \\
3 & Flying Scotsman & 0.098 \\
4 & Raveningham Hall & 0.095 \\
5 & Flying Scotsman & 0.099 \\
6 & 7F Class 2-8-0 53808 & 0.081 \\
7 & Raveningham Hall & 0.089 \\
8 & Flying Scotsman & 0.108 \\
\hline
\end{tabular}

\subsection{Environmental Considerations}

Weather conditions during the testing were varied throughout the day, with periods of heavy rain intermixed with periods of sunshine. As the sensors are not completely waterproof, a number of tests were performed with plastic bags on the sensors to protect the sensors from excessive rainfall. Whilst every effort is made to limit the amount of air in the bag and to reduce the possibility of buffeting, the bags can cause excess background noise during measurements. During the analysis of the results, the noise produced by the plastic bags was found to be negligible.

\section{RESULTS}

This section presents the measured rotations and deflections recorded during the aforementioned testing. For each steam locomotive, the measured rotation and deflection plots presents a clear peak for the locomotive followed by smaller peaks of equal amplitude representing the trailing carriages. Within the peak of the locomotive, it is also possible to determine the orientation of the tender and the engine, as the engine is responsible for the larger peak. The reduced diesel locomotive weight results in a measured rotations and displacements similar to the carriages behind.

\subsection{Rotation Data}

Rotation of the bridge under loading was calculated using the method proposed in Section 3.1. The maximum rotation of the bridge under loading from each locomotive is presented in Figure 6. The measured maximum rotation for each loading scenario is presented in Table 3.

Rotation was measured in the longitudinal direction. The maximum rotation was always measured at the abutment furthest away from the approaching trains for the steam engines.

The maximum rotation of $0.108^{\circ}$ was recorded at Test Point 5, the western abutment, under loading from the Flying Scotsman (Train 8), with the other two passings of the train measuring a rotation of $0.098^{\circ}$ to $0.099^{\circ}$.
The Raveningham Hall displayed smaller rotations than the Flying Scotsman locomotive, with a maximum measured rotation of $0.095^{\circ}$. Though the Raveningham Hall has a greater axle load than the Flying Scotsman, the heavier weight of the Flying Scotsman results in larger rotations.

Only a single measurement was recorded for the 7F Class 2-8-0 53808 steam engine. The maximum rotation measurement recorded for engine was $0.081^{\circ}$, which was expected for the lighter engine. Following this trend, the maximum measured rotation for the diesel locomotive was significantly smaller, with a maximum deck rotation of $0.044^{\circ}$.

The same carriages are used to form each train, but it can be seen that the rotations caused by the carriages following the Flying Scotsman are the highest. As each of the Flying Scotsman journeys were operating at full capacity, the increased rotations are likely to be a resultant of the increased live load of these carriages.

\subsection{Deflection Data}

Deflection was calculated at the mid-span of the bridge using the method proposed in Section 3.2. The maximum deflection calculated for each locomotive is presented in Figure 7, plotted against the measured deflections from the Imetrum data. The measured deflection at mid-span and quarter-span for each train is presented in Table 4.

The maximum deflection measured was 7.00 $\mathrm{mm}$ for Train 3, the Flying Scotsman. The higher deflection for Train 3 can be attributed to the train travelling at a faster speed during this passing of the train. The speed of the train was determined from determining the entry and exit times of the train on the bridge. Similar to the rotation measurements, the Raveningham Hall deflections measurements were marginally smaller, with a maximum measured deflection of $6.58 \mathrm{~mm}$.

The correlation between the deflection measurements recorded for the Flying Scotsman and the Raveningham Hall indicate that the increased weight of the Flying Scotsman has a negligible effect on the bridge.

The deflection measurements for the carriages exhibit a similar trend to the rotation data, with increased deflections measured for the carriages following the Flying Scotsman locomotive.

Prior to the Flying Scotsman arriving to the railway, essential maintenance was carried out by the bridge owner to ensure the bridge was capable of carrying the increased size of the locomotive. 


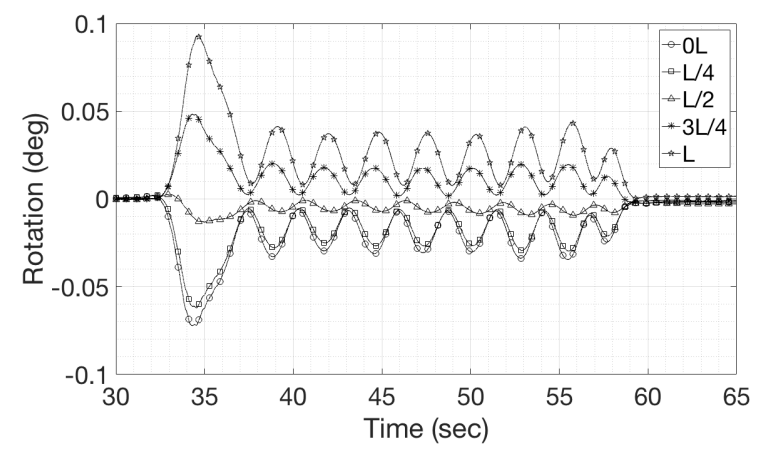

(a)

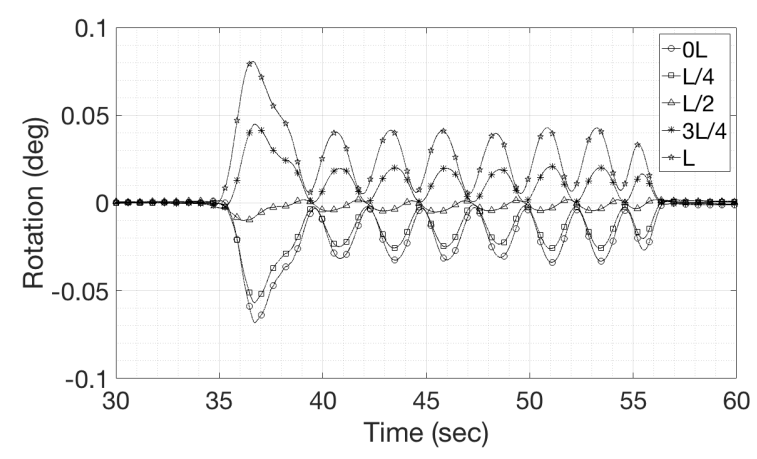

(c)

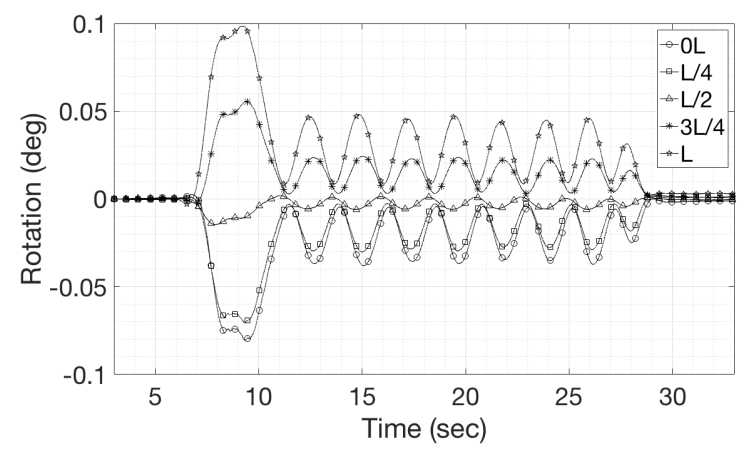

(b)

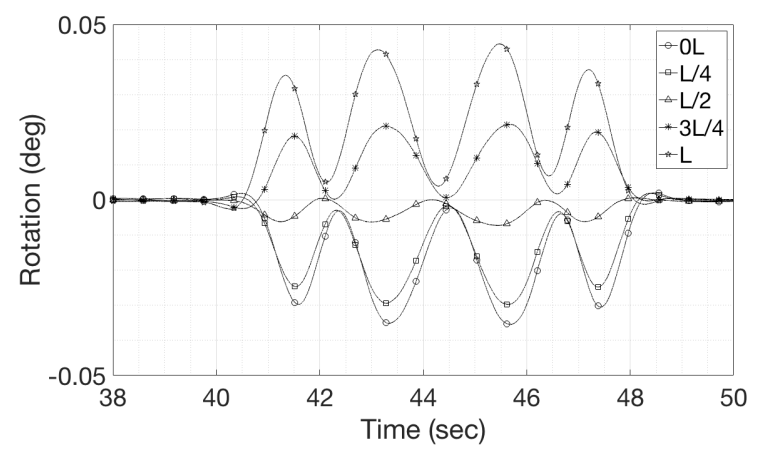

(d)

Figure 6: Rotations from accelerometer data under different train loads, (a) Raveningham Hall (Train 1), (b) Flying Scotsman (Train 3), (c) 7F Class 2-8-0 53808 ( Train 6) and (d) Diesel (Train 2)

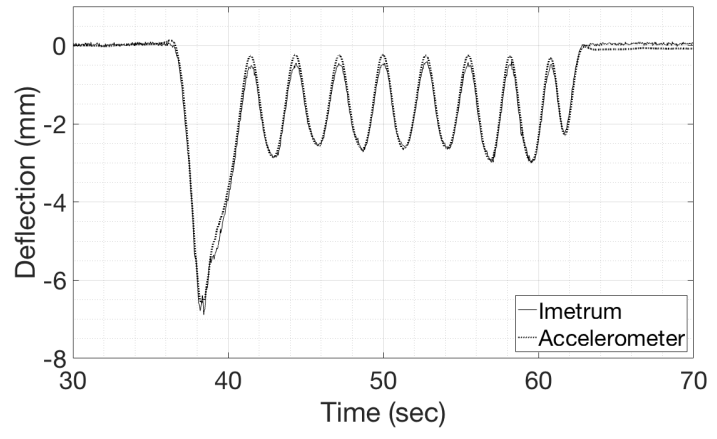

(a)

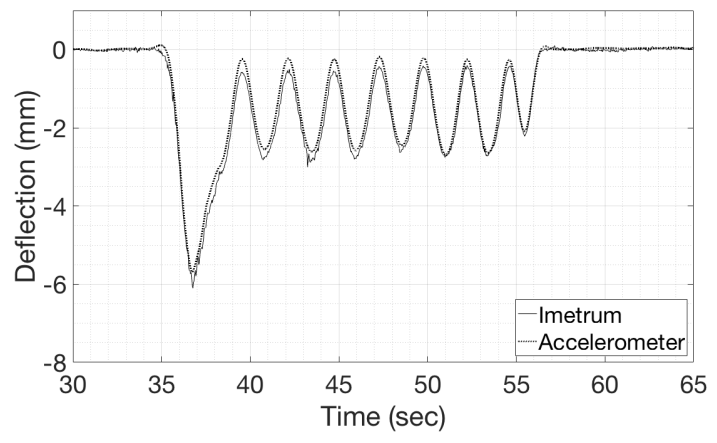

(c)

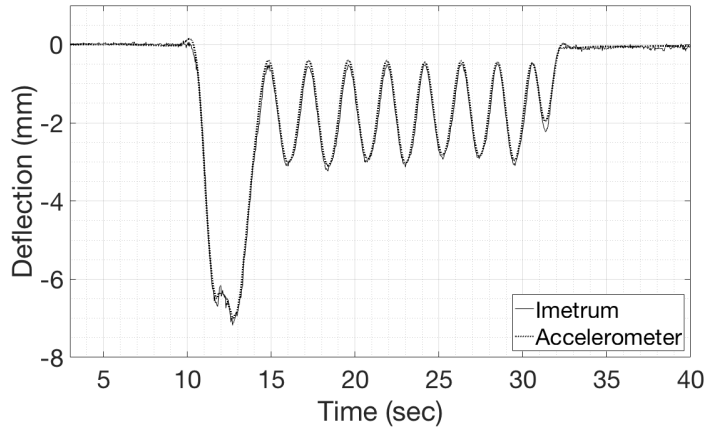

(b)

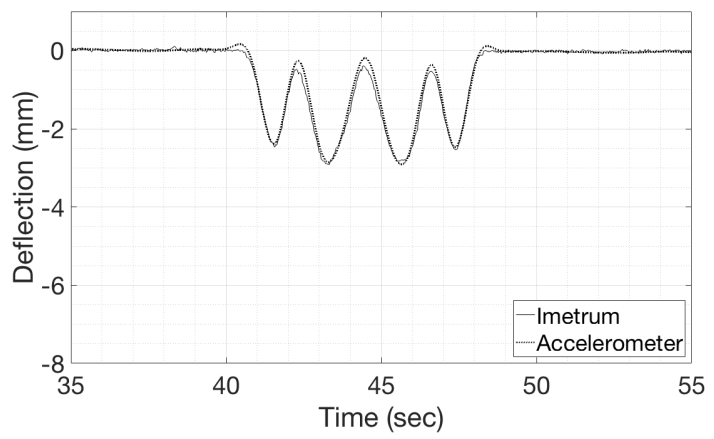

(d)

Figure 7: Deflections at mid-span under different train loads , (a) Raveningham Hall (Train 1), (b) Flying Scotsman (Train 3), (c) 7F Class 2-8-0 53808 ( Train 6) and (d) Diesel (Train 2) 
Table 4: Deflections calculated from measured rotations

\begin{tabular}{cll} 
Train & Locomotive & $\begin{array}{c}\text { Deflection } \\
\text { at Mid-Span } \\
{[\mathrm{mm}]}\end{array}$ \\
\hline 1 & Raveningham Hall & 6.58 \\
2 & Diesel & 2.91 \\
3 & Flying Scotsman & 7.00 \\
4 & Raveningham Hall & 6.44 \\
5 & Flying Scotsman & 6.63 \\
6 & 7F Class 2-8-0 53808 & 5.70 \\
7 & Raveningham Hall & 6.16 \\
8 & Flying Scotsman & 6.80 \\
\hline
\end{tabular}

The results of this study confirm that the bridge has sufficient capacity to carry heavier locomotives than the Raveningham Hall.

\section{POTENTIAL FOR FURTHER WORK}

The next aim for the study is to construct a standalone data monitoring system that is easily adaptable and transportable, to allow for monitoring of the wider transport network.

\section{CONCLUSIONS}

The purpose of this test was to establish how the Mineral Line bridge performs when subjected to different loading conditions, including the passing of the Flying Scotsman. Accelerometers were situated at five test points along the deck to measure deflections and rotations. The calculated deflection at mid-span was compared against measured deflections from the Imetrum camera positioned at mid-span of the bridge.

The results of the testing showed that the bridge experiences greater magnitude of deflections and rotations under the Flying Scotsman locomotive to those experienced through passage of the other locomotives. The diesel engine, which was the lightest of all the engines, resulted in the lowest measured deflections and rotations.

The correlation between the deflection measured by the Imetrum camera and the deflection calculated using the technique proposed here proves that a small number of accelerometers are sufficient to determine the performance of a bridge under train loading.

\section{ACKNOWLDGEMENTS}

The team would like to acknowledge the continued support of the West Somerset Railway, particularly David Depoix and Andrew Young.

\section{REFERENCES}

Brownjohn, J. M. W., A. De Stefano, Y.-L. Xu, H. Wenzel, \& A. E. Aktan (2011). Vibration-Based Monitoring of Civil
Infrastructure: Challenges and Successes. Journal of Civil Structural Health Monitoring 1(3-4), 79-95.

Connolly, L., A. O. Connor, C. Leahy, \& C. Bowe (2016). Monitoring and Maintenance of the Boyne Viaduct. In Civil Engineering Research in Ireland 2016 (CERI2016), Volume 1.

Deng, L., W. Wang, \& Y. Yang (2015). State-of-the-Art Review on the Causes and Mechanisms of Bridge Collapse. Journal of Performance of Constructed Facilities 30(2).

Elsaid, A. \& R. Seracino (2012). Vibration Based Damage Detections of Scour in Coastal Bridges. Homeland Security Affairs, Supplement 4, Article 2.

Helmi, K., T. Taylor, A. Zarafshan, \& F. Ansari (2015). Reference free method for real time monitoring of bridge deflections. Engineering Structures 103, 116-124.

Rytter, A. (1993). Vibrational Based Inspection of Civil Engineering Structures. Ph. D. thesis, Aalborg University.

Sohn, H. \& C. R. Farrar (2001). Damage Diagnosis using Time Series Analysis of Vibration signals. Smart Materials and Structures 10(3), 446-451.

Sung, S. H., J. W. Park, T. Nagayama, \& H. J. Jung (2013). A multi-scale sensing and diagnosis system combining accelerometers and gyroscopes for bridge health monitoring. Smart Materials and Structures 23(1), 015005.

van Leeuwen, Z. \& R. Lamb (2014). Flood and Scour Related Failure Incidents at Railway Assets Between 1846 and 2013. Project W13-4224. JBA Trust 30.

Webb, G. T., P. J. Vardanega, \& C. R. Middleton (2014). Categories of SHM Deployments: Technologies and Capabilities. Journal of Bridge Engineering 20(11). 